\title{
COMPARISON OF COMPLETE BLOOD COUNTS OF STABLE COPD PATIENTS AT TWO DIFFERENT ALTITUDE IN TURKEY.
}

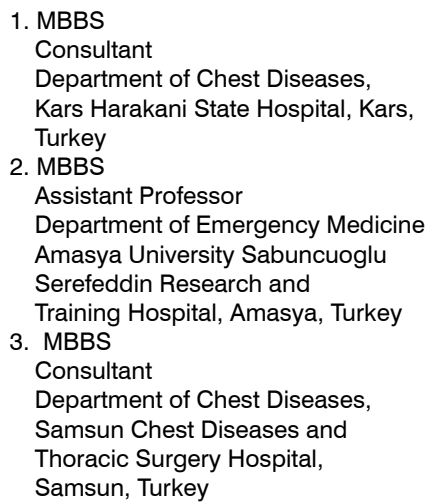

Correspondence Address: Dr. Gokhan Perincek, MD Kars Harakani State Hospital Pulmonology Diseases Department 36000, Kars, Turkey.

md.gokhanperincek@gmail.com

Article received on: 29/06/2019

Accepted for publication: 25/08/2019

Received after proof reading: 28/08/2019

\begin{abstract}
Gokhan Perincek', Sema Avcl', Ilker Yılmam ${ }^{3}$
ABSTRACT... Introduction: The aim of this study was to evaluate how altitude difference affects complete blood count (CBC) in patients with stable Chronic Obstructive Pulmonary Disease (COPD). Study Design: Cross-sectional study. Setting: Department of Pulmonology, Kars Harakani State Hospital (Group 1) and Samsun Chest Diseases and Thoracic Surgery Hospital (Group 2), Turkey. Period: Six months. From March to September 2018. Material and Methods: A total of 400 patients ( 200 female, 200 male) with stable COPD were included. For each group, 100 female and 100 male patients were randomly selected from hospitals. Age, BMI $\left(\mathrm{kg} / \mathrm{m}^{2}\right)$, comorbidity, smoking status, $\mathrm{CBC}$ were evaluated. Hemoglobin, hematocrit, WBC, MPV, platelet, lymphocyte count and percentage, platelet/lymphocyte rate (PLR), neutrophil count and percentage, neutrophil /lymphocyte rate (NLR), eosinophil count and percentage, PDW, PCT were recorded. Results: Patients living at high altitude were significantly older, had lower weight and had lower FEV1 levels. COPD stages of Group 1 patients were more severe $(p<0.001)$. There were no moderate COPD patients in this group and the patients had fewer comorbidities (43\%). Hemoglobin, hematocrit, MPV, WBC, neutrophil count and percentage, NLR and PLR were significantly higher in Group $1(p<0.001)$. PDW, PCT, lymphocyte count and percentage, eosinophil count and percentage were significantly higher in Group 2 patients $(p<0.001)$. Conclusion: Hemoglobin, hematocrit, MPV, WBC, neutrophil count and percentage, NLR and PLR were higher in patients living at high altitude. PDW, PCT, lymphocyte count and percentage, eosinophil count and percentage were significantly higher in patients living at low altitude.
\end{abstract}

Key words: $\quad$ Altitude, Chronic Obstructive Pulmonary Disease, Complete Blood Count.

Article Citation: Perincek G, Avci S, Yilmam I. Comparison of complete blood counts of stable COPD patients at two different altitude in Turkey. Professional Med $\mathrm{J}$ 2019; 26(9):1518-1523. DOI: 10.29309/TPMJ/2019.26.09.3861

\section{INTRODUCTION}

Chronic obstructive pulmonary disease (COPD) is a global health problem and the third leading cause of mortality worldwide. ${ }^{1,2}$ COPD is a common disease characterized by improperly reversible airflow limitation and alveolar abnormalities. ${ }^{1,2}$ The most important risk factors for COPD are smoking, air pollution, age, tuberculosis exposure, socioeconomic status and additionally geographical differences. ${ }^{3}$ Around 400 million people live in high altitude (>1500 meters above sea-level) and this geographical altitude is associated with COPD prevalence, and adaptation mechanism of these patients. ${ }^{4}$ In COPD patients living in high altitude areas, altitude could induce a higher growth of airways relative to lung size, causing to an increased FEV1/FVC ratio and it may cause chronic hypoxia. ${ }^{5}$
In high altitude, to compensate for the low pressure of oxygen, many physiological changes occur in the human blood circulation. In response to hypoxia, the humanbody adapts to the tissues by increasing the distribution of oxygen. Firstly, it is expected that the hemoglobin concentration of circulating hemoglobin concentration will increase from the complete blood count parameters. ${ }^{6}$

Studies on how altitude affects patients with healthy individuals and COPD are quite common. In this study, we focused on how altitude difference affects complete blood count parameters in patients with stable COPD.

\section{METHODS}

Study Design

This cross-sectional study was performed after 
ethical committee approval with the parameters of 400 patients (200 female, 200 male) with known COPD and presented to Kars Harakani State Hospital, Kars, Turkey (called Group 1) and Samsun Chest Diseases and Thoracic Surgery Hospital, Samsun, Turkey (called Group 2) between March 2018 and September 2018. The parameters of the patients were obtained from the electronic data bank of the hospital. The study included the patients with known stable COPD who admitted to Chest Diseases Clinics of two different hospitals. For each group, 100 female and 100 male patients were randomly selected from both hospitals.

The evaluated parameters which belong to the patients are: age, height (meter), weight $(\mathrm{kg})$, BMl $\left(\mathrm{kg} / \mathrm{m}^{2}\right)$, COPD stages, comorbidity, smoking status (smoker, ex-smoker, never smoker). The results of complete blood cell count of the patients provided hemoglobin $(\mathrm{g} / \mathrm{dL})$, hematocrit (\%), white blood cell (WBC, $\left.\times 10^{3} \mu \mathrm{l}\right)$, mean platelet volume (MPV, fL), platelet count $\left(\times 10^{3} \mu \mathrm{l}\right)$, lymphocyte count $\left(\times 10^{3} \mu \mathrm{l}\right)$, lymphocyte percentage $(\%)$, platelet/lymphocyte rate (division of platelet count in lymphocyte count, (PLR) neutrophil count $\left(\times 10^{3} \mu \mathrm{l}\right)$, neutrophil percent $(\%)$, neutrophil /lymphocyte rate (division of neutrophil count in lymphocyte rate, NLR), eosinophil count $\left(\times 10^{3} \mu \mathrm{l}\right)$, eosinophil percent (\%), platelet distribution width (PDW, fL) plateletcrit (PCT, \%). COPD was based on Global Initiative for Chronic Obstructive Lung Disease (GOLD) criteria for the diagnosis, classification and severity. ${ }^{7}$ Spirometry was done with Spirolab III-MIR, Italy. Subsequently, patients were staged according to the severity criteria of GOLD. ${ }^{7}$; stage I (FEV1 $\geq 80 \%$ ), stage II (50\% $\leq$ FEV $1<80 \%)$, stage III $(30 \% \leq F E V 1<50 \%)$ and stage IV (FEV1<30\%). ${ }^{7}$

\section{Blood Samples}

All blood samples were drawn from the vein in the forearm and collected into $2 \mathrm{~mL}$ Lavender (EDTA) top tube and were analysed with Pentra DF Nexus, Horiba Medical, Japan with Automated Cell Counter Methodology. The blood samples were stabilized optimally when run within in 4 hours of collection, stable for 24 hours at room temperature, and stable for 36 hours at $2-8$ degrees $\mathrm{C}$.

\section{Altitude Differences}

Kars, located in the northeast of Turkey, is a city which is 1768 meters above sea level. ${ }^{8}$ In our country, Kars is one of the cities with the highest altitude. ${ }^{9}$ Samsun, located in the north of Turkey, is a city which is 4 meters above sea level. ${ }^{9}$ In our country, is one of the cities with the lowest altitude. ${ }^{9}$

\section{Statistical Analysis}

Parameters were analyzed with SPPS for Windows 23.0 version. The mean of the continuous variables in descriptive statistics was expressed with standard deviation; categorical variables were expressed with numbers and percentages. The significance of the difference between the groups was evaluated with Chi-Square Test. Mann-Whitney $U$ Test was used in comparison of binary groups. Kruskal Wallis Test was used in comparison of groups more than two. $p<0.005$ value was accepted to be statistically significant.

\section{RESULTS}

Baseline characteristic features of patients are presented in Table-I. Patients living at high altitude were significantly older, had lower weight and had lower FEV1 levels. COPD stages of Group 1 patients were more severe $(p<0.001)$. There were no moderate COPD patients in Group 1 and the patients had fewer comorbidities (43\%). In Group 1 , most of the patients were ex-smoker and never smoker (84.5\%).

In Group 2, mild and moderate patient groups were higher (60\%). In this group, the number of patients with additional diseases was higher $(57.5 \%)$ and the number of smoker patients were higher than ex-smoker and never smoker (44.5\%). Complete blood count parameters are presented in Table-II. Hemoglobin, hematocrit, MPV, WBC, neutrophil count, neutrophil percentage, NLR and PLR were significantly higher in Group 1 compared to Group 2 patients $(p<0.001)$. PDW, PCT, lymphocyte, lymphocyte percentage, eosinophil and eosinophil percent were significantly higher in Group 2 compared to Group 1 patients $(p<0.001)$. 


\begin{tabular}{|c|c|c|c|c|}
\hline & \multicolumn{3}{|c|}{ COPD Groups } & \multirow{3}{*}{ P-Value } \\
\hline & Total & Group 1 & Group 2 & \\
\hline & \multicolumn{3}{|c|}{ Mean \pm sd / n (\%) } & \\
\hline Age & $66.6 \pm 9.7$ & $68.4 \pm 9.7$ & $64.7 \pm 9.3$ & $<0.001$ \\
\hline \multicolumn{4}{|l|}{ Gender } & \multirow{3}{*}{ NS } \\
\hline Female & $200(50 \%)$ & $100(50 \%)$ & $100(50 \%)$ & \\
\hline Male & $200(50 \%)$ & $100(50 \%)$ & $100(50 \%)$ & \\
\hline Length (meter) & $1.6 \pm 0.1$ & $1.6 \pm 0.1$ & $1.6 \pm 0.1$ & NS \\
\hline Weight (kg) & $73 \pm 15.1$ & $71.2 \pm 15.2$ & $74.9 \pm 14.8$ & 0.021 \\
\hline BMI (kg/m2) & $27.9 \pm 5.9$ & $27.4 \pm 6.1$ & $28.4 \pm 5.7$ & NS \\
\hline FEV1 & $47.3 \pm 19.9$ & $39 \pm 15.2$ & $55.6 \pm 20.6$ & $<0.001$ \\
\hline \multicolumn{4}{|l|}{ Group } & \multirow{5}{*}{$<0.001$} \\
\hline Mild $\geq 80 \%$ & $32(8 \%)$ & - & $32(16 \%)$ & \\
\hline Moderate $50 \% \leq \mathrm{FEV} 1<80 \%$ & $142(35.5 \%)$ & $54(27 \%)$ & $88(44 \%)$ & \\
\hline Severe $30 \% \leq \mathrm{FEV} 1<50 \%$ & $135(34.0 \%)$ & 79 (39.5\%) & $57(28.5 \%)$ & \\
\hline Very Severe FEV1<30\% & $90(22.5 \%)$ & 67 (33.5\%) & $23(11.5 \%)$ & \\
\hline \multicolumn{4}{|l|}{ Comorbidity } & \multirow{3}{*}{0.004} \\
\hline Exist & $201(50.3 \%)$ & $86(43 \%)$ & $115(57.5 \%)$ & \\
\hline Absent & $199(49.8 \%)$ & $114(57 \%)$ & $85(42.5 \%)$ & \\
\hline \multicolumn{4}{|l|}{ Smoking Status } & \multirow{4}{*}{$<0.001$} \\
\hline Smoker & $120(30 \%)$ & 31 (15.5\%) & $89(44.5 \%)$ & \\
\hline Ex-Smoker & 151 (37.8\%) & $86(43 \%)$ & 65 (32.5\%) & \\
\hline Never Smoker & 129 (32.3\%) & 83 (41.5\%) & $46(23 \%)$ & \\
\hline
\end{tabular}

Table-I. Baseline characteristics features of Group 1 and Group 2 patients

\begin{tabular}{|l|c|c|c|c|}
\hline & \multicolumn{3}{|c|}{ COPD Groups } \\
\cline { 2 - 4 } & Total & Group 1 & Group 2 & P-Value \\
\hline Hemoglobin & \multicolumn{3}{|c|}{ Mean / n(\%) } & \\
\hline Hematocrit & $14.14 \pm 2.91$ & $15.18 \pm 2.06$ & $13.09 \pm 3.26$ & $<0.001$ \\
\hline MPV & $42.6 \pm 11$ & $46.3 \pm 6.5$ & $38.8 \pm 13$ & $<0.001$ \\
\hline Platelet count (x10^3) & $7.86 \pm 1.24$ & $8.21 \pm 0.97$ & $7.51 \pm 1.37$ & $<0.001$ \\
\hline PDW & $258.2 \pm 82$ & $255.1 \pm 79.3$ & $261.3 \pm 84.6$ & NS \\
\hline PCT & $17.9 \pm 15$ & $16.8 \pm 0.7$ & $18.9 \pm 21.1$ & $<0.001$ \\
\hline WBC (x10^3) & $0.69 \pm 9.91$ & $0.2 \pm 0.06$ & $1.19 \pm 14.05$ & 0.021 \\
\hline Lymphocyte count & $10.46 \pm 6.07$ & $11.24 \pm 4.69$ & $9.66 \pm 7.12$ & $<0.001$ \\
\hline Lymphocyte (\%) & $1.96 \pm 1.45$ & $1.55 \pm 0.94$ & $2.37 \pm 1.73$ & $<0.001$ \\
\hline Neutrophil count & $20.9 \pm 12$ & $15.9 \pm 11$ & $25.9 \pm 10.9$ & $<0.001$ \\
\hline Neutrophil (\%) & $7.6 \pm 4.97$ & $8.68 \pm 4.57$ & $6.52 \pm 5.12$ & $<0.001$ \\
\hline Eosinophil count & $71.4 \pm 26.7$ & $77.5 \pm 34.8$ & $65.3 \pm 12.2$ & $<0.001$ \\
\hline Eosinophil (\%) & $0.17 \pm 0.28$ & $0.16 \pm 0.31$ & $0.19 \pm 0.26$ & $<0.001$ \\
\hline NLR & $1.9 \pm 2.7$ & $1.5 \pm 2.5$ & $2.2 \pm 2.8$ & $<0.001$ \\
\hline PLR & $6.38 \pm 9.76$ & $8.91 \pm 12.37$ & $3.86 \pm 5.02$ & $<0.001$ \\
\hline
\end{tabular}

COPD, chronic obstructive pulmonary disease; continuous variables are expressed as mean \pm standard deviation; NS, non-significant; MPV, mean platelet volume; PDW, platelet distribution width; PCT, plateletcrit; WBC, white blood cell; NLR, neutrophil-to-lymphocyte ratio; PLR, platelet-to-lymphocyte ratio.

Table-II. Complete blood count parameters of Group 1 and Group 2 patients 


\section{DISCUSSION}

Our results demonstrate that patients living at high altitude were significantly older, had lower weight and had lower FEV1 levels. COPD stages of these patients were more severe. None of the patients in this group had mild COPD. Moreover, the patients in this group had fewer comorbidities and most of the patients were ex-smoker and never smoker. Patients living at low altitude, mild and moderate COPD stages were higher. In addition, the number of patients with comorbidities and smoking were higher. In patients with low altitude, smoking and comorbidities are high, however, moderate COPD levels in these patients may be attributed to age and less exposure to hypoxia. COPD is a disease with increasing prevalence and severity with age. ${ }^{10}$ Cumulative exposure to smoking and pollution, telomere shortening and dysfunction, decreased vital capacity in the aging lung, reduced recoil, mucociliary clearance, mucosal immunity and decreased vascular reserve may increase the severity of the disease with age. ${ }^{10}$ It is known that deterioration of gas exchange will be impaired by exposure to hypoxic environment in patients with COPD. ${ }^{11}$

In this study, hemoglobin, hematocrit, MPV, WBC, neutrophil count, neutrophil percentage, NLR and PLR were higher in patients living at high altitude. Increased hemoglobin and hematocrit in patients living at high altitude is an expected adaptation to more oxygen uptake in tissues. In these patients, higher MPV indicates increased platelet function and aggregation. Although these patients are stable, the number of neutrophils and the high percentage may be due to their severity of disease and frequent use of steroids. In the study of AlSweedan et al., hemoglobin, MPV and leukocyte counts were significantly higher in patients living at high altitude. ${ }^{12}$ Stress hormones secreted at high altitude may also increase neutrophil count and decrease lymphocyte count. ${ }^{13}$ Increased neutrophil counts and decreased lymphocyte counts cause NLR and TLR to increase in this group of patients.

PDW, PCT, lymphocyte, lymphocyte percentage, eosinophil and eosinophil percentage were significantly higher in patients living at low altitude.
PDW is one of the markers of platelet activation. High PDW is an indicator of inflammatory process and hypercoagulability. ${ }^{14}$ PDW is expected to be higher in COPD patients compared to healthy people. ${ }^{14}$ There are studies showing that PDW is correlated with increasing age and MPV. ${ }^{15}$ In our study, there is a reverse finding for PDW. Smoking may disrupt the morphology of platelets and cause PDW to be high in this group. PCT is a measure of total platelet mass and MPV is the average size of platelets. PCT and MPV are parameters that can be affected by comorbid conditions in age group patients like our study. ${ }^{16}$ PCT was expected to increase in patients with severe COPD, but in our study, it was low. ${ }^{17}$ In the study of Zhang et al., PCT was negatively correlated with age, but not with low altitude. ${ }^{15}$ The number and percentage of lymphocytes were lower in Group 1. Lymphocyte is the expected parameter to decrease in older age and more advanced lung disease. Low lymphocyte count is a physiological adaptation mechanism of the immune system to increasing age. ${ }^{18}$ Additively, lymphocyte count is expected to decrease at high altitude. ${ }^{19}$ Eosinophilia in patients living at low altitude may be attributed to better response to steroid treatment and greater number in the early stage. The high rate of smoking in this group may cause eosinophilia. ${ }^{20,21,22}$

The inclusion of only two centers in the study, the low number of patients and the high number of patients with severe COPD in Group 1 are the limitations of the study.

\section{CONCLUSION}

In conclusion, hemoglobin, hematocrit, MPV, WBC, neutrophil count, neutrophil percentage, NLR and PLR were higher in patients living at high altitude. PDW, PCT, lymphocyte, lymphocyte percentage, eosinophil and eosinophil percent were significantly higher in patients living at low altitude.

\section{Copyright@ 25 Aug, 2019.}

\section{REFERENCES}

1. Xiong W, Xu M, Zhao Y, Wu X, Pudasaini B, Liu J. Can we predict the prognosis of COPD with a routine blood test? Int J Chron Obstruct Pulmon Dis 2017; 12 : 615-25. 
2. Pascual-González Y, López-Sánchez M, Dorca J, Santos $S$. Defining the role of neutrophil-to-lymphocyte ratio in COPD: A systematic literature review. Int J Chron Obstruct Pulmon Dis 2018; 13: 3651-62.

3. Chan TC, Chiang PH, Su MD, Wang HW, Liu MS. Geographic disparity in chronic obstructive pulmonary disease (COPD) mortality rates among the Taiwan population. PLoS ONE 2014; 9(5): e98170.

4. Brakema EA, Tabyshova A, Kasteleyn MJ, Molendijk E, van der Kleij RMJJ, van Boven JFM, Emilov B. High COPD prevalence at high altitude: Does household air pollution play a role? Eur Respir J 2019;1801193. https://doi.org/10.1183/13993003.01193-2018.

5. Horner A, Soriano JB, Puhan MA, Studnicka M, Kaiser $B$, Vanfleteren LEGW, et al. Altitude and COPD prevalence: Analysis of the Prepocol-Platıno-BoldEPI-Scan study. Resp Res 2017; 18:162.

6. Windsor JS, Rodway GW. Heights and haematology: The story of haemoglobin at altitude. Postgrad Med J 2007; 83(977): 148-51.

7. The global Initiative for chronic obstructive lung disease (GOLD) [Internet]. Spirometry For Health Care Providers. Updated June; 2010. [cited 2018 December 12]. Available from: http://goldcopd.org/ gold-reports-2017/.

8. Available from: http://www.kars.gov.tr/kars-ili-cografiyapisi. [cited 2019 January 18].

9. Available from:https://www.ozelliklerinedir.com/illerinyukseklik-ozellikleri-rakimlari/ [cited 2019 January 18].

10. Incalzi RA, Scarlata S, Pennazza G, Santonico M, Pedone $\mathrm{C}$. Chronic obstructive pulmonary disease in the elderly. Eur J Intern Med 2014; 25:320-28.

11. Stream JO, Luks AM, Grissom CK. Lung disease at high altitude. Expert Rev Respir Med 2009; 3(6): 635-50.

12. Al-Sweedan SA, Alhaj M. The effect of low altitude on blood count parameter. Hematol Oncol Stem Cell Ther 2012; 5(3): 158-61.

13. Beıdleman BA, Muza SR, Fulco CS, Cymerman A, Staab JE, Sawka MN, et al. White blood cell and hormonal responses to $\mathbf{4 3 0 0} \mathrm{m}$ altitude before and after intermittent altitude exposure. Clin Sci 2006; 111:163-69. doi:10.1042/CS20060012
14. Białas AJ, Pedone C, Piotrowski WJ, Incalzi RA. Platelet distribution width as a prognostic factor in patients with COPD - pilot study. Int J Chron Obstruct Pulmon Dis 2017; 12:2261-67.

15. Zhang J, Li M, He Y. Large population study for ageand gender- related variations of platelet indices in Southwest China healthy adults. Hematol Transfus Int J 2015;1(4):108-14.

16. Agrawal A, Kumar S, Bhagwati J. Correlation of platelet Indices with clinical profile in elderly patients: A study in rural teaching hospital. Ann Med Health Sci Res 2018; 8:163-69.

17. Kalemci S, Akin F, Sarihan A, Sahin C, Zeybek A, Yilmaz. The relationship between hematological parameters and the severity level of chronic obstructive lung disease. Pol Arch Intern Med 2018; 128(3):171-77. doi: 10.20452/pamw.4198

18. Acanfora D, Scicchitano $P$, Carone M, Acanfora C, Piscosquito G, Maestri R, et al. Relative lymphocyte count as an indicator of 3-year mortality in elderly people with severe COPD. BMC Pulm Med 2018; 18(1):116. doi: 10.1186/s12890-018-0685-6.

19. Nanzigu S, Waako P, Petzold M, Kiwanuka G, Dungu H, Makumbi $F$, et al. CD4-T-Lymphocyte reference ranges in uganda and its influencing factors. Lab Med 2011; 42(2).

20. Ho J, He W, Chan MTV, Tse G, Liu T, Wong SH, et al. Eosinophilia and clinical outcome of chronic obstructive pulmonary disease: A meta-analysis. Sci Rep 2017; 7: 13451.

21. Jensen EJ, Pedersen B, Narvestadt E, Dahl R. Blood eosinophil and monocyte counts are related to smoking and lung function. Respir Med 1998; 92(1):63-9.

22. Song JH, Lee $\mathrm{CH}$, Kim JW, Lee WY, Jung JY, Park JH, et al. Clinical implications of blood eosinophil count in patients with non-asthma-COPD overlap syndrome COPD. Int J Chron Obstruct Pulmon Dis 2017; 12:245564. 


\section{AUTHORSHIP AND CONTRIBUTION DECLARATION}

\begin{tabular}{|c|c|c|c|}
\hline Sr. \# & Author-s Full Name & Contribution to the paper & Author $=\mathbf{s}$ Signature \\
\hline 1 & Gokhan Perincek & 1st Author & $\operatorname{Com}_{28.06 .2219}$ \\
\hline 2 & Sema Avcı & 2nd Author & \\
\hline 3 & Ilker Yılmam & 3rd Author & 28 ive $701^{6}$ \\
\hline
\end{tabular}

